\title{
Could some epigenetic modifications hold the key to opposing the metabolic syndrome?
}

\author{
Giovanni Tarantino ${ }^{1,2, *}$, Matteo Nicola Di Minno ${ }^{1, *}$ and Carmine Finelli3,* \\ ${ }^{1}$ Department of Clinical Medicine and Surgery, Federico II University Medical School of Naples, Via Sergio Pansini, Naples, \\ Italy \\ ${ }^{2}$ Centro Ricerche Oncologiche di Mercogliano, Istituto Nazionale Per Lo Studio E La Cura Dei Tumori "Fondazione Giovanni \\ Pascale", IRCCS, Italy, Italy \\ ${ }^{3}$ Department of Emergency and Internal Medicine, Ospedale S. Maria della Pietà - ASL Napoli 3 Sud, Nola (Na), Italy \\ * These authors have contributed equally to this work
}

Correspondence to: Giovanni Tarantino, email: tarantin@unina.it

Keywords: non alcoholic fatty liver diseases, metabolic syndrome, epigenetics, microRNAs, PUFAs

Received: January 27, $2016 \quad$ Accepted: December 12, $2016 \quad$ Published: December 21, 2016

\section{ABSTRACT}

The role of epigenetic mechanisms in the pathogenesis of diseases has been increasingly recognized over recent years. Due to the intrinsic flexibility of the chromatin structure both in response to diet and environment, and as a result of foreseeable therapeutic interventions, epigenetics has emerged as a promising conceptual frame to investigate chronic degenerative disorders. This applies particularly to diet-driven and environment-driven metabolic disorders, such as obesity and its complications, including atherosclerosis and non-alcoholic fatty liver diseases (NAFLD). Current evidence strongly suggests that chronic inflammation is a landmark of obesity, atherosclerosis, and NAFLD, and that markers of inflammation are important predictors of cardiovascular risk factors. A crucial question is how pro-inflammatory gene expression patterns are established and maintained in the aforementioned illnesses.

Epigenetic gene regulation is a partially new entry in the field of cardiovascular diseases. Epigenetic modifications provide attractive candidate disease mechanisms by explaining, in principle, how diet, environment and lifestyle might impose aberrant gene expression patterns in the individual's lifetime, which can also be considered the result of trans-generational epigenetic inheritance.

The main long-term goals in this field are to identify and understand the role of the epigenetic marks that could be used as early predictors of metabolic risk, and possibly develop drugs or diet-related treatments able to delay these epigenetic changes or even reverse them.

Therefore, a continued and greater understanding of these mechanisms will eventually help identify individuals at high risk of the Metabolic Syndrome, and develop therapeutic interventions, in accordance with current global government strategy, utilizing also PUFA rich foods.

\section{INTRODUCTION}

The term epigenetics refers to heritable changes in gene expression (active versus inactive genes) that do not involve modifications in the underlying DNA sequence, i.e., a change in phenotype without a change in genotype. An epigenetic change is a regular and natural occurrence but can also be influenced by several factors, including age, environment/lifestyle, and diseases. Epigenetic modifications usually manifest as the manner in which cells eventually differentiate to lead to hepatocytes or myocytes. On the other hand, epigenetic changes have also harmful effects that may end up in neoplasms. At least three systems including DNA methylation, histone modification and non-coding RNA (ncRNA)-associated 
gene silencing are currently considered to initiate and sustain epigenetic changes [1]. New and ongoing research is continuously unraveling the role of epigenetics in a variety of human disorders and fatal diseases.

Due to the intrinsic flexibility of the chromatin structure both in response to diet and environment, and as a result of foreseeable therapeutic interventions, epigenetics has emerged as a promising conceptual frame to investigate chronic degenerative disorders [2]. This applies particularly to diet-driven and environmentdriven metabolic disorders, such as obesity and its complications, including atherosclerosis and nonalcoholic fatty liver diseases (NAFLD). Consequently, a number of researches have investigated the occurrence of abnormal DNA methylation patterns during the natural history of obesity, atherosclerosis and NAFLD, and also whether lipoproteins and other relevant molecules can elicit any epigenetic responses. These applications have demonstrated that native lipoproteins, selected fatty acids and homocysteine among others factors, can modulate DNA methylation [3, 4]. One particularly important and fascinating issue in the epigenetic theory of metabolic diseases is the transgenerational transmission of risk [5]. Epigenetic stability, both within and across generations, will also depend on the degree and predictability of environmental variation, dispersal patterns, and the (epi) genetic architecture underlying phenotypic responses to the environment [6]. Bienertová-Vašků et al. [7] proposed a novel definition, i.e., "stress entropic load", referring to the actual energetic cost of an individual's adaptation, and suggest that it be used to weigh the likelihood that a transgenerational response is induced once it is individualized and/or calculated.

Consequently, the inadequate establishment of epigenetic modifications during critical developmental periods due to changes in the maternal diet or other environmental factors may induce pediatric developmental diseases and even affect health in adulthood [8]. Since much of the reprogramming that occurs during early life may go unrecognized until adulthood, a better understanding of the interplay between genetic and epigenetic interaction in critical time windows of development would improve our ability to determine individual susceptibility to a wide range of diseases [8]. Marian et al. highlighted that transgenerational epigenetics, referring to microRNAs, could play a determinant role in the heritability of coronary atherosclerosis [9]. Among epigenetic modifications, microRNAs (miRNAs) have also been studied largely in NAFLD. miRNAs are small, normally occurring, single stranded RNA molecules regulating miRNAs degradation or translation inhibition, consequently altering protein expression of target genes. One miRNAs can target multiple genes (multiplicity) and multiple miRs may target a single gene (cooperativity). Since the first discovery in 1993, many miRNAs in various organisms have been determined. It has been hypothesized that the accurate characterization of the mechanisms underlying miRNA transcription regulation could expand our knowledge and give new insights on homeostatic and pathobiological networks [10]. Aim of DIANA-miRGen v3.0 (http://www. microrna.gr/mirgen) is to provide for the first time accurate cell-line-specific miRNA gene transcription start sites, coupled with genome-wide maps of transcription factor binding sites in order to unveil the mechanisms of miRNA transcription regulation. To this end, more than 7.3 billion RNA-, ChIP- and DNase-Seq next generation sequencing reads were analyzed/assembled and combined with stateof-the-art miRNA transcription start sites prediction and transcription factor binding site identification algorithms. Both the new database schema and web interface facilitate user interaction and provide advanced queries and innate connection with other DIANA resources for miRNA target identification and pathway analysis. The database currently supports 276 miRNA transcription start sites that correspond to 428 precursors and $>19 \mathrm{M}$ binding sites of 202 transcription factor on a genome-wide scale in nine cell-lines and six tissues of Homo sapiens and Mus musculus [10].

The expression of miRNAs is both organ-specific and dependent on the stage of development. miRNAs influence at least one third of all human transcripts and are known regulators of important cellular processes, e.g., cell metabolism, cell proliferation, apoptosis, immune function, tissue development and differentiation [11-16].

We summarize the recent contributions to the field of epigenetic effects (Tab. 1) that influence the development of obesity, atherosclerosis, and NAFLD - all important predictors of cardiovascular risk factors, as well as the protective effect of polyunsaturated fatty acids (PUFAs).

\section{OBESITY AND EPIGENETIC}

As developing and emergent nations transition out of poverty, their populations often face the problem of significant excess abdominal fat, and extraordinarily high rates of type II diabetes mellitus, hypertension, coronary heart disease, NAFLD and cancer [17-22]. Obesity could be defined as a heterogeneouc, multifactorial disease. It is evident that better understanding of the mechanisms underlying the interactions between lifestyle, environment, and genetics is critical to developing effective strategies for prevention and treatment. Body weight gain usually grows over time. But, scales cause subjects to focus on body weight rather than enabling them to focus on how much body fat and lean mass they have acquired. Signs of obesity include: a higher than normal body mass index and waist circumference. The existing and future impact on public health of these chronic metabolic diseases is immense; indeed, an obese society has been recognized by the pharmaceutical industry as a lucrative market. Actually, attention has directed to deepening the role of 
epigenetic changes in the etiology of obesity. It has been argued that the epigenome could represent the mechanistic link between genetic variants and environmental factors in determining obesity risk. Major international efforts are underway to explore and document how DNA sequence polymorphisms influence an individual's predisposition to obesity and its comorbidities [23-30]. Such variations in DNA sequence offer hope of a personalized medicine where therapeutics are tailored and matched with patients presenting a particular genotype [31-35]. Recent advances of whole genome association studies have led to the identification of common DNA sequence variants associated with obesity and type II diabetes mellitus in selected cohorts, such as diabetic patients [36-38].

Epigenetics, as stated above, is the study of mitotically heritable alterations in the gene expression potential not caused by changes in the DNA sequence [39]. Transient environmental influences during development can cause permanent changes in epigenetic gene regulation, and accumulating evidence links epigenetic dysregulation to human disease [40]. There are currently three major objectives in epigenetic research in relation to obesity: search for epigenetic biomarkers to predict future health problems or detect individuals at greater risk; understand the obesity-related environmental factors that could modulate gene expression by affecting epigenetic mechanisms, and study novel therapeutic strategies based on nutritional or pharmacological agents to modify epigenetic marks [41].
Following the intriguing hypothesis of the developmental origins of health and diseases, obesity during pregnancy is a clear risk for the health and wellbeing of the offspring later in adulthood [42]. Attig et al. [42] found that adipose tissue was characterized by a noticeable dysregulation of gene expression, specifically by an upregulation of genes entailed in lipid storage and adipocyte hypertrophy/hyperplasia, in obese mice born to lean and obese mothers, respectively.

As hypothesized by Attig et al. [42], the offspring of lean and obese mice unambiguously varied in terms of several metabolic features and epigenetic marks, suggesting that the effects of a high fat diet are based on the mother's being lean or obese, independently of whether the offspring is lean (resistant) or obese (sensitive),

Dick et al. [43] suggested that the pathways involved in the perturbation of the hypoxia-inducible transcription factor could play a decisive role, impacting the response to the increased weight occurring in humans, and possibly acting on overfeeding-induced insulin resistance.

Gillberg et al. [44] showed that young men who had a low birthweight exhibit epigenetic alterations in their adipose tissue that potentially influence insulin resistance and risk of type 2 diabetes..

Analogously, maternal obesity during pregnancy and/or lactation could alter hormonal or other signaling mechanisms that affect the morphological development of the fetal or postnatal hypothalamus, with permanent consequences on the body weight of the offspring [45].

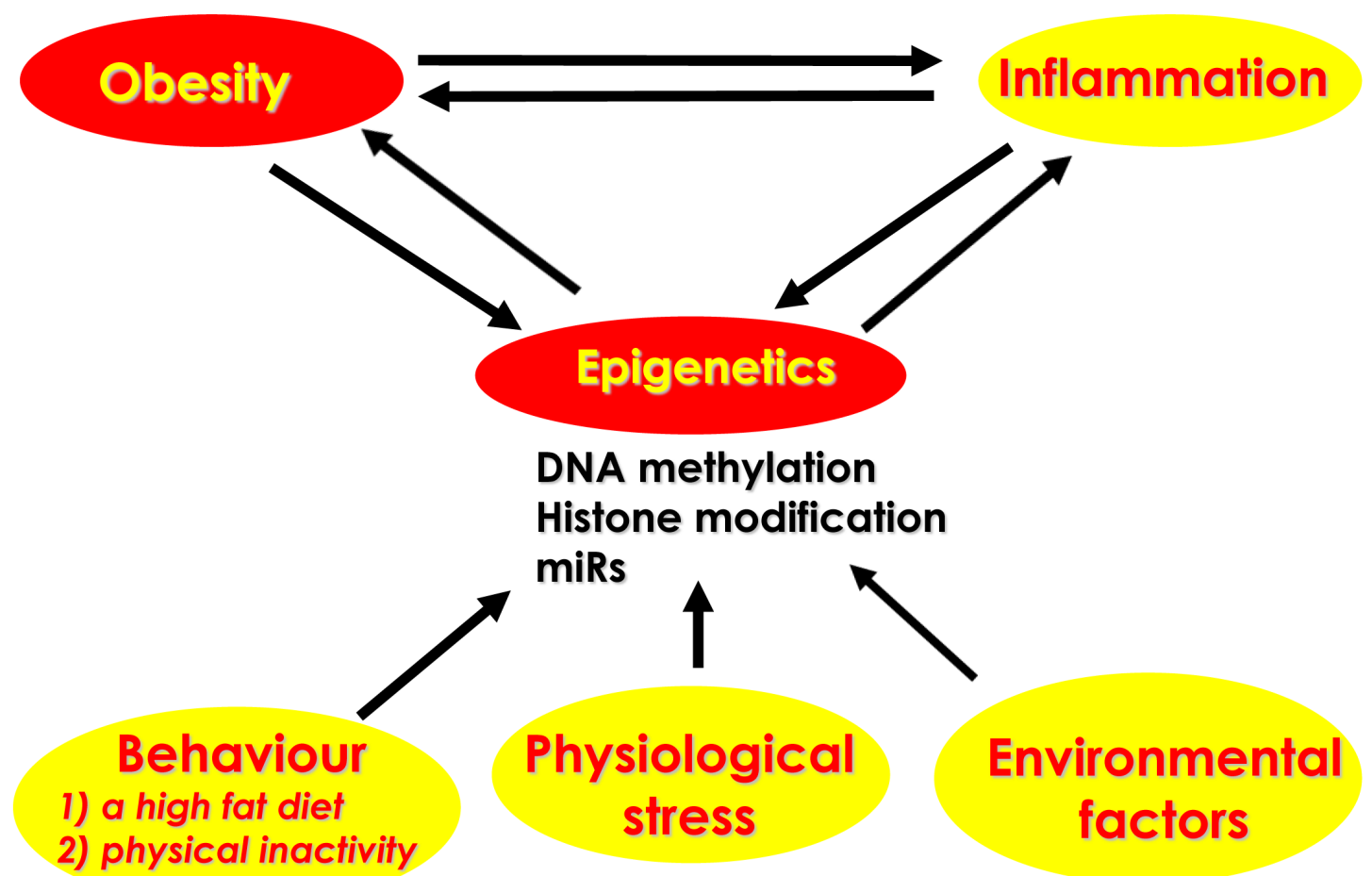

Figure 1: The interaction between obesity and epigenetics. 
In addition to these morphological effects, maternal obesity could affect hypothalamic development at the epigenetic level [40]. All monogenic forms of human obesity are associated with mutations affecting leptin signaling in the hypothalamus. The most common forms of monogenic obesity in humans are caused by mutations in the gene encoding melanocortin 4 receptor (MC4R) [24], which integrates opposing peptide signals from the arcuate nucleus.

Therefore, according to Drummod et al. [46] maternal diet during fetal development bears many epigenetic implications affecting the offspring's risk factors for obesity during childhood and adulthood, which may last in subsequent generations. Genes associated with the risk of obesity, being susceptible to epigenetic mutations, impact subsequently on specific disease mechanisms, i.e., impaired glucose tolerance and insulin sensitivity, as well as appetite [46].

Bayol et al. [47] found that adiposity was more prominent in female than male offspring, and gene expression analyses showed increased levels of insulinlike growth factor-1 (IGF-1), insulin receptor substrate (IRS)-1, vascular endothelial growth factor (VEGF)-A (according to data by Tarantino et al. in obese patients with NAFLD [48]), peroxisome proliferator-activated receptorgamma (PPARgamma), leptin, adiponectin, adipsin, lipoprotein lipase (LPL), Glut 1, Glut 3, but not Glut 4 mRNA expression in females fed a so called "junk food diet" throughout the study, compared to females never given access to junk food. Li et al. [49] suggested that maternal obesity and type II diabetes mellitus cause latent metabolic defects and widespread epigenetic changes in isogenic mice. Indeed, as reported by Gilbert et al. [50], further studies aiming at better understanding the way epigenetic regulation of gene expression controls $\beta$-cell function could discover potential therapeutic targets for the prevention and treatment of type II diabetes mellitus.

It is widely accepted that offspring exposed to both maternal undernutrition and obesity, or gestational type II diabetes mellitus have an increased risk for chronic diseases later in life, lending again credence to the theory of the early origins of chronic diseases, as reported by Ruchat et al. [51].

The growing epidemics of obesity and type II diabetes mellitus is largely attributed to the current lifestyle comprising over-consumption and physical inactivity [52]. Future studies designed to further explore and integrate the epigenetic mechanisms with lifestyle modification may lead to interdisciplinary interventions and novel preventive options for mitochondrial alteration and metabolic disorders [52].

Figure 1 summarizes the interaction between different stress factors and pathophysiological processes in obesity. Behavior as well as physiological and environmental stress conditions impair epigenetic control mechanisms, further exacerbating the inflammation state in adipocytes, in circulatory and inflammatory cell tissue in obese subjects.

We need to learn a great deal more about the developmental epigenetics of the genes playing a relevant role in body-weight regulation, and the potential of early environment to influence these processes.

\section{ATHEROSCHLEROSISANDEPIGENETICS}

Atherosclerosis is a chronic inflammatory disease of large and intermediate size arteries, triggered by vascular infiltration of lipid particles (some of which are oxidized), endothelial activation, macrophage infiltration, and foam cell formation. Atherosclerosis develops as an asymptomatic process for decades due to the compensatory enlargement of the arteries at all plaque locations, with consequently no effect on blood flow. What is more, a discrete part of plaque ruptures do not lead to any symptoms until enough narrowing or closure of an artery, due to clots, occurs. On the contrary, patients may have signs and symptoms of the disease when some arteries are affected (coronary arteries, carotid arteries, peripheral arteries). Traditionally, it has been assumed that the uptake of oxidized lipoproteins by macrophage scavenger receptors is largely responsible for the initiation of this process. However, Nicolaou et al. [53] showed that cholesterol (Chol) and the necrotic cell debris developing in the atheromating lesions - currently viewed as harmless, might potentially contribute to disease progression via Toll-like receptor (TLR)-dependent lipid body formation in specialized cells, i.e., macrophages.

These data highlight the link between lipid excessrelated inflammation and innate immune response pathways, independent of lipoprotein oxidation.

Slevin et al. [54] compared the features of coronary and carotid plaque and evaluated their association with end-point ischaemic events; they found differences in the genetic contribution to plaque development as well as in the deregulation of gene and protein expression and cellular signal transduction activity of active cells in selected regions particularly susceptible to thrombosis [54]. The differences between carotid and coronary artery plaque development might clarify the diversity in anatomo-pathological appearance and risk of rupture [54] - a well-known health hazard.

Wierda et al. [55] underscored the prominent role of macrophages in the pathogenesis of atherosclerosis giving importance to chronic inflammation in both the initiation and progression of vascular remodeling. Furthermore, gene regulatory proteins (transcription factors) and epigenetic mechanisms are central to the transcriptional con trol of gene expression and similarly important for modifying the accessibility of chromatin by DNA methylation and histone modifications [55]. Epigenetic modulators are centrally implicated in the regulation of vascular, immune and tissue-specific gene expression 
within the atherosclerotic lesion It should be pointed out that epigenetic processes are reversible and might provide an excellent thorough therapeutic target [55]. Epigenetic regulation is gradually assuming more importance, being recognized as a main factor in the pathogenesis of atherosclerosis [55]. Although subsequent clinical studies have shown that the causal relationship between folate and vitamin B deficiency, atherogenesis, and aberrant DNA methylation is not clear [56], the innovative idea that DNA hypomethylation is associated with atherosclerosis has been confirmed experimentally [57]. ABSTR

Jiang et al. [58] showed that DNA methylation pattern in atherosclerosis is quite complex and depends on the genetic background as well as on many related environmental risk factors. Wang J et al. [59] suggested that the monocyte chemoattractant protein-1 (MCP-1) promoter DNA hypomethylation, through the nuclear factor- $\kappa \mathrm{B} / \mathrm{DNA}$ methyltransferase 1 (NF- $\kappa \mathrm{B} / \mathrm{DNMT} 1)$, might lead to atherosclerosis under conditions of hyperhomocysteinemia in ApoE

(-/-) mice. Ma et al. [60] showed that hyperhomocysteinemia induces cardiac injury by up-regulation of the p53-dependent pro-apoptotic related genes Noxa and Bax, while p53 DNA levels of hypomethylation, analyzed by nested methylation-specific$\mathrm{PCR}$, are involved in the pathological process induced by hyperhomocysteinemia in ApoE (-/-) mice. Delaney et al. [61] infer that atherosclerosis is an inflammatory process of the arterial wall mediated by cells of both innate and adaptive immunity, and that T-lymphocytes play an important role in arranging the immune response causing progression of atherosclerosis .

Yoo et al. [62], in an attempt to establish the correlation between epigenetic alterations and obesityrelated abnormalities, examined the DNA methylation status in C57BL/6J obese mice fed an atherogenic diet, and concluded that hypermethylation of repetitive DNA elements in the livers of atherogenic diet-fed mice suggest epigenetic changes due to nutritional intervention.

In addition, Kim et al. [63] suggested that focal epigenetic changes in the estrogen beta receptor provide both the evolving processes of atherosclerosis and vascular aging. Moreover, Wang YS et al. [64] showed that miRNA-152 decreases under pro-atherosclerotic conditions and the decreased microRNA-152 might counteract the inhibitory effect on DNA methyltransferase, which leads to hypermethylation of the estrogen receptor- $\alpha$ gene and reduces the estrogen receptor- $\alpha$ level . Testing whether statin and a traditional Chinese medicine (SanHuang-Xie-Xin-Tang, SHXXT) exert a therapeutic effect on miRNA, DNA methyltransferases and estrogen receptor $\alpha$ methylation, these Authors found that statins were unable to reverse the proatherosclerotic changes, but that SHXXT showed a promising inhibitory effect on this unwanted signaling pathway [64].

Chen et al. [65] showed that oxidized low-density lipoprotein (oxLDL) greatly intensifies the migration of primary human aortic smooth muscle cells (HASMC),

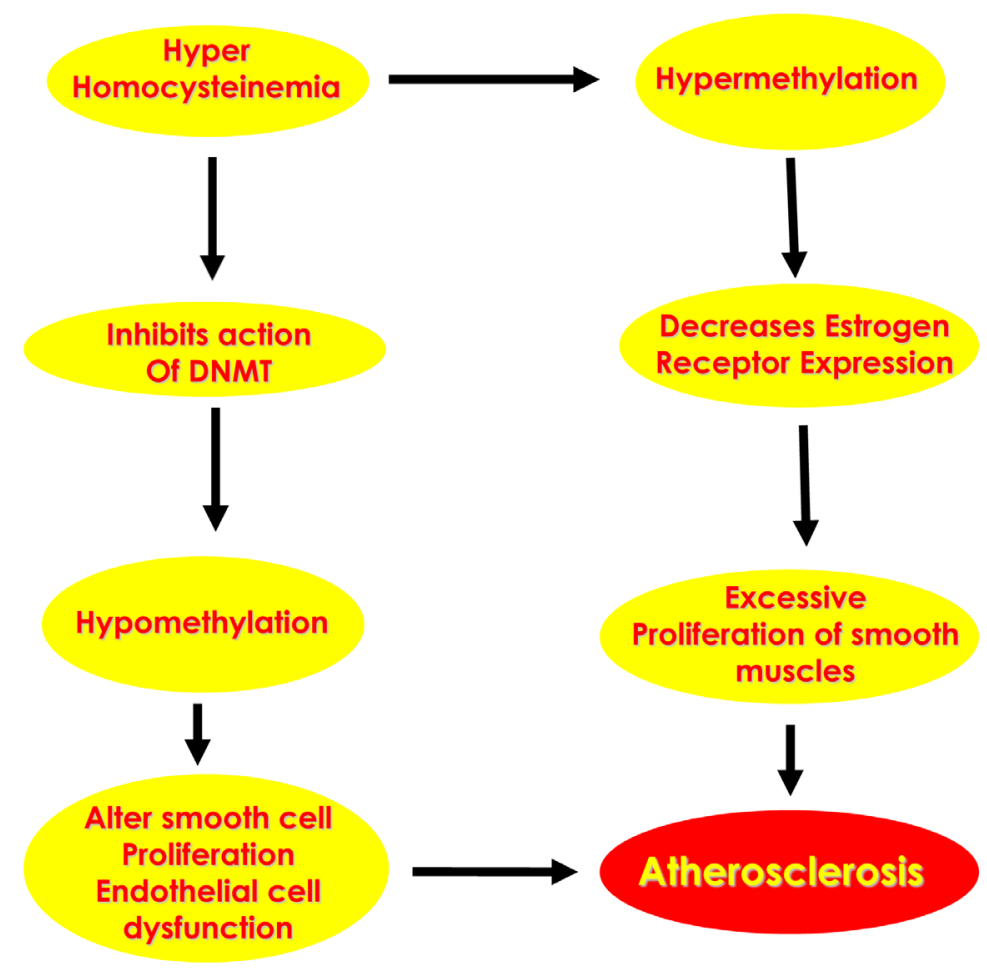

Figure 2: Epigenetic effects reacted to atherosclerosis. 
through the matrix metalloproteinase (MMP)-2/MMP-9 up-regulation associated with decreased DNA methylation levels. In oxLDL-mediated primary human aortic smooth muscle cells (HASMCs), both miRNAs and protein levels of DNA methyltransferase $3 b$ (DNMT3b) resulted in a dose-dependent down-regulation [65]. Therefore, these results confirm that miRNAs-mediated epigenetic regulation may be a new interesting mechanism in determining atherosclerosis [65].

It is widely accepted that low-density lipoprotein (LDL) Chol causes endothelial dysfunction and is a major modifiable risk factor for atherosclerosis. Endothelial Kruppel-like Factor 2 (KLF2) is a transcription factor central to endothelium-dependent vascular homeostasis and LDL represses endothelial KLF2 expression via DNA and histone methylation, as reported by Kumar et al. [66]. Downregulation of KLF2 by LDL leads to a dysfunctional, hypercoagulable status of the endothelium [66] and, consequently, to atherosclerosis. Moreover, Yamada et al. [67] have identified hypo- and hypermethylated genes related to atherosclerosis by a genome-wide analysis of DNA methylation. Thus, both hypo- and hypermethylation end up with altered smooth muscle cell proliferation, a decisive contributor to atherosclerotic lesions (Figure 2).

\section{NAFLD AND EPIGENETICS}

NAFLD is one of the most common forms of chronic liver diseases and a cause of elevated serum aminotransferases worldwide. The prevalence of NAFLD in the general population of Western countries ranges from $20 \%$ to $30 \%$ [68-70]. Due to the alterations in dietary structure and life style, the prevalence of NAFLD in developing countries has been increasing rapidly [71, 72].

Available evidence underlines how NAFLD is associated with the metabolic syndrome (MetS), which comprises obesity, type II diabetes mellitus, dyslipidemia and high blood pressure - with insulin resistance being the central mechanism. NAFLD is presently considered the hepatic manifestation of MetS [20, 22, 71, 73-75]. Most people with NAFLD have few or no symptoms. They may complain of fatigue, malaise, and dull right-upperquadrant abdominal discomfort. Mild jaundice may be noticed although this is rare. More commonly NAFLD is diagnosed following abnormal laboratory liver tests during routine blood tests or by the means of abdominal ultrasound.

It is habitually believed that environmental and genetic factors interact to produce the NAFLD phenotype and determine its progression. On the other hand, the detailed pathogenesis determining which individuals develop NAFLD remains unclear. At present, the emerging field of epigenetics has shed light on the pathogenesis of chronic liver disease including NAFLD $[76,77]$. Elucidation of genetic and epigenetic factors that predispose an individual to NAFLD may lead to the development of non-invasive biomarkers for early diagnosis of NAFLD and may allow early preventive and therapeutic strategies for high risk individuals.

The roles of epigenetics in the pathogenesis of NAFLD are largely unknown, but growing evidence is appearing [78-80].

There are as-yet-undiscovered molecular aspects of the biological roles played by miRNAs in the liver, especially in relation to lipid, glucose, drug, and iron metabolism as vital functions of the liver, as well as important therapeutic targets [80, 81].

Lakner et al. [82] provided detailed contribution to the exciting field of miRNAs and their impact on liver development and the broad spectrum of NAFLD, from simple fatty liver to cirrhosis, with particular emphasis on hepatic stellate cells and the potential use of miRNAs as therapeutic tools. MiRNAs have been suggested as possible therapeutic targets for the treatment of NAFLDrelated liver damage and as novel therapeutic target to enhance liver regeneration capability [83]. It's discussed the experimental evidence of miRNAs both as potential non-invasive markers to assure early diagnosis and as suggestive therapeutic targets in the more advanced stages of NAFLD and as a promoter for hepatocyte proliferation and cell growth [83].

MiRNA-122 is abundantly elevated in the liver and is a key factor in determining glucose and lipid metabolism [84]. Miyaki et al. [84] suggested that hepatic and serum miRNA-122 levels were associated with hepatic steatosis and fibrosis. Particularly, serum miRNA-122 levels could be a useful marker in predicting liver fibrosis in patients with NAFLD [84]. Subsequently, the roles played by miRNA-122 in the pathogenesis of NAFLD have been confirmed by other studies. Recently, serum levels of miR-34a and miR-122 have been found to be significantly higher among NAFLD patients, and positively correlated to VLDL-C and triglyceride levels [85]. Thus, circulating miR-34a and miR-122 can be used as potential biomarkers for discriminating NAFLD patients from healthy controls [85]. [All these findings strongly support the relevant role of miRNA-122 in regulating lipid metabolism and thus its likely contribution to the development of NAFLD. Zhang et al. [86], vice versa, showed that increased miRNA$15 \mathrm{~b}$ expression in NAFLD animal models might lead to decreased cell proliferation and glucose consumption rate while inducing the storage of intracellular triglyceride the true hazards of NAFLD. Therefore, increased serum miRNA-15b levels are also another potential biomarker for the diagnosis of NAFLD [86]. Estep et al. [87] reported that miRNA expression from visceral adipose tissue could contribute to the pathogenesis of NAFLD - a finding that may differentiate relatively simple steatosis from non-alcoholic steatohepatitis (NASH). The latter finding could help identify potential targets for pharmacological treatment regimens and candidate biomarkers for NASH [87]. Based on growing evidence supporting key roles 
for miRNAs in regulating both Chol and fatty acid metabolism, miRNAs are of considerable interest as potential drug targets to modulate lipid and lipoprotein metabolism [88]. Dysregulation of miRNAs disrupts gene regulatory network, leading to metabolic syndrome and its related diseases [88], Therefore, miRNA-based therapeutics hold considerable promise in fighting the growing epidemic of obesity and type II diabetes mellitus and the associated risk of atherosclerosis and NAFLD. Based on available evidence, several miRNAs, some of which epigenetically regulated, are up- and/or downregulated during NAFLD development [89]. Nevertheless, the essential role played in NAFLD by the Polycomb Group protein Enhancer of Zeste Homolog 2 (EZH2), which controls the epigenetic silencing of specific genes and/or miRNAs by trimethylating Lys 27 on histone H3, is still unidentified. [89]. The nuclear expression/activity of the EZH2 protein is down-regulated both in liver derived from animal models of NAFLD and in cultured cells, i.e., the free fatty acid-treated HepG2, as demonstrated by Vella et al. [89]. The decrease in EZH2 is negatively related to: (a) lipid accumulation; (b) the expression of pro-inflammatory markers, including TNF- $\alpha$ and TGF- $\beta$; and (c) the expression of miRNA-200b and miRNA-155 [89]. Consistently, the pharmacological inhibition of EZH2 by 3-Deazaneplanocin A (DZNep) significantly subsides EZH2 expression/activity, while increasing lipid accumulation, inflammatory cytokines/acute phase proteins and microRNAs [89]. Therefore, the defective activity of EZH2 might accelerate NAFLD development by enhancing ectopic fat storage and the de-repression of both the inflammatory genes and specific miRNAs, as suggested by Vella et al. [89]. According to Pirola et al., hepatic methylation and transcriptional activity of the mitochondrially-encoded NADH dehydrogenase 6 (MTND6) are associated with NAFLD severity, as assessed by histology [90]. Epigenetic changes of mitochondrial DNA are potentially reversible through direct interventional programs, such as physical activity, due to its ability to modulate the methylation status of MT-ND6 [90]. However, whether exercise could prevent NAFLD via targeting microRNA is unclear, but recently some data link the benefit of exercise and miR-212 downregulation in preventing NAFLD via targeting fibroblast growth factor-21, a key regulator for lipid metabolism [91].

Bruce et al. [92] showed that maternal high-fat feeding predisposed adult mice offspring to NASH, by involving hepatic mitochondrial dysfunction and altered lipogenesis gene expression.

Figure 3 illustrates the probable interaction between several stress conditions that impair epigenetic control mechanisms exacerbating the already high degree of inflammation in visceral adipose tissue and circulatory and tissue inflammatory cells in subjects with NAFLD.

\section{POLYUNSATURATED FATTY ACIDS (PUFAS) AND EPIGENETICS}

In recent years, it has been demonstrated that polyunsaturated fatty acids (PUFA) have an antiinflammatory effect and act as regulators of lipid metabolism. However, the epigenomic mechanisms

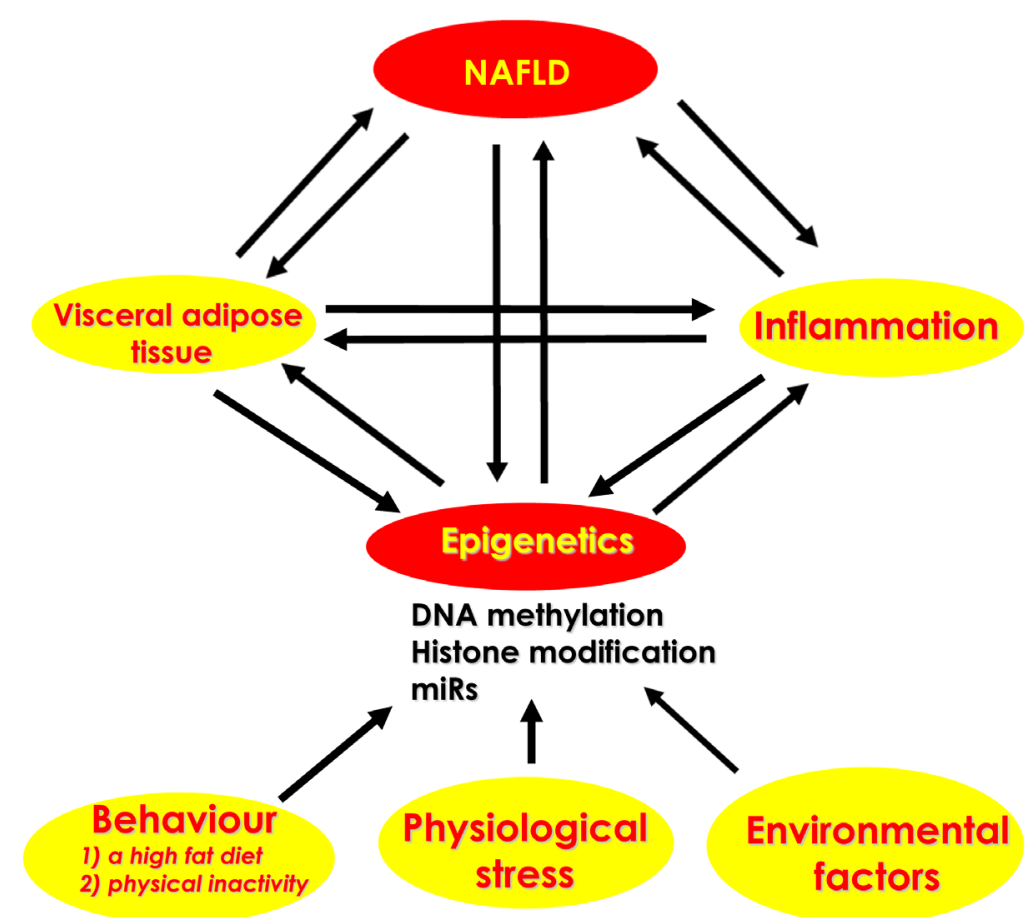

Figure 3: The probable interaction between NAFLD and epigenetics. 
involved in these processes are not thoroughly known. Epidemiological studies have revealed how favorable dietary patterns, such as the Mediterranean diet during pregnancy and early childhood can have a protective effect, with reduced risk of obesity, diabetes, cardiovascular risk factor, some cancers and NAFLD [9397]. Particularly, these beneficial effects reflect composite dietary patterns, and are difficult to attribute to a single dietary element. However, a number of studies have taken a 'component' approach to demonstrate the specific immunomodulatory properties of individual dietary components such as vitamins, minerals and long-chain polyunsaturated fatty acids (LCPUFA) [98]. Modulation of gene expression through epigenetic changes is one important mechanism by which dietary exposures can lead to changes in immune development [99]. The epigenetic program regulates all aspects of mammalian development, including developmental timing and expression of immune genes. The relative differences in immune gene expression between neonates and adults are associated with differences in epigenetic profiles reflecting the role of epigenetics in immune development [100-102]. External environmental pressure such as dietary exposure can lead to subtle variations in the epigenetic regulation of immune gene expression, that can potentially lead to more profound effects on subsequent immune function, clinical phenotype and disease risk [103-105]. The local tissue microenvironment is an important determinant of immune development. Changes in the local tissue milieu can modify the pattern of effector response probably also through epigenetic changes [106]. Environmental factors that modify the local microenvironment thus have a significant potential to alter immune programming and the propensity for inflammation. Therefore, several dietary factors (such as LCPUFA and antioxidants) have known effects on tissue elements as a result of their influence as metabolic components, substrates or structural elements of cells and tissues, with downstream effects on gene expression through a number of various pathways [107, 108]. LCPUFA are good examples of dietary factors with multiple metabolic and structural functions influencing the propensity for inflammation.

Experimental findings lend credence to the fact that plasma membrane (PM)-associated signaling and, hence, cell metabolism and viability depend on lipid composition and organization [109]. Jaureguiberry et al. [109], by developing a cell model to study the endogenous effects of PUFAs on PM properties, analyzed its influence on Chol homeostasis. They further expanded their studies to a cell model over-expressing both $\Delta 5$ and $\Delta 6$ desaturases, which resulted in a permanently higher PUFA content in PM [109]. This cell line showed increased PM fluidity, Chol storage, and mitochondrial activity [109]. What is more, human apolipoprotein A-I-mediated Chol removal was less efficient in these cells than in the corresponding control [109]. Taken together, these results suggest that cell functionality was preserved by regulating PM organization and Chol exportation and homeostasis [109]. Docosahexaenoic acid (DHA) supplementation is known to protect against acute ethanol-induced hepatic steatosis, which may be associated with reduced expression of hepatic stearoyl-CoA desaturase-1 (SCD-1) and production of inflammatory cytokines, as demostrated by Huang et al. [110].

In recent years, previously unrecognized chemical mediators derived from polyunsaturated fatty acids, involved in controlling the acute inflammatory response by activating local resolution programs, have been identified. [111] Among them are the so-called specialized pro-resolving lipid mediators (SPMs), which include lipoxins (LX), resolvins (Rv), protectins (PD), and maresins (MaR), whose property is to be enzymatically biosynthesized during resolution of self-limited inflammation [111]. Each one of these possesses distinct chemical structures and regulates cellular pathways by their ability to activate pro-resolving G-protein coupled receptors (GPCRs) in a stereospecific manner [111]. For instance, RvD1 controls several miRNAs of interest in self-limited acute inflammation, counter-regulating the mediators inducing and worsening inflammation [111]. Recchiuti et al. [111] overviewed some of the biosynthesis and mechanisms of SPM actions, mainly focusing on the recently reported miRNAs implicated in their pro-resolving responses, ending up with beneficial actions in regulating the onset of inflammation and its rapid resolution. The elucidation of these mechanisms operating in vivo to maintain acute inflammation within limits as well as stimulate resolution, have opened novel opportunities to target inflammation-based diseases via activating resolution mechanisms [111]. Maternal dietary supplementation with n-3 PUFAs during pregnancy has proven to increase gestation length, enhance fetal growth and reduce the risk of pregnancy complications, although the precise mechanisms on which these effects are based remain to be clarified, as reported by Jones et al. [112]. Omega-3 PUFAs are involved in several physiological pathways, which could account for these effects, including anti-inflammatory, pro-resolving and anti-oxidative pathways [112]. Some studies have shown that maternal dietary n-3 PUFA supplementation during rat pregnancy can reduce placental oxidative damage and increase placental levels of pro-resolving mediators beneficial effects coupled to enhanced fetal and placental growth [112]. Because several placental disorders, such as intrauterine growth restriction, preeclampsia and gestational diabetes mellitus, are associated with increased placental inflammation and oxidative stress, there is growing interest in the potential for dietary n-3 PUFAs as therapeutic approach for these disorders [112]. Habitual diets rich in dark-green vegetables are associated with 
Table 1: Epigenetic effects related to different metabolic diseases

\begin{tabular}{|c|l|}
\hline Metabolic diseases & \multicolumn{1}{c|}{ Epigenetic effects } \\
\hline Obesity & $\begin{array}{l}\uparrow \text { appetite } \\
\uparrow \text { insulin resistance } \\
\uparrow \text { adiposity } \\
\uparrow \text { inflammation }\end{array}$ \\
\hline Atheroschelorosis & $\begin{array}{l}\downarrow \text { estrogen receptor expression } \\
\text { p proliferation of smooth muscles } \\
\uparrow \text { smooth cell proliferation } \\
\uparrow \text { endothelial cell dysfunction }\end{array}$ \\
\hline NAFLD & $\begin{array}{l}\uparrow \text { fibrosis } \\
\uparrow \text { storage of intracellular triglyceride } \\
\uparrow \text { inflammatory molecules } \\
\uparrow \text { hepatocyte proliferation } \\
\uparrow \text { cell growth }\end{array}$ \\
\hline
\end{tabular}

a prompt response to $\omega-3$ fatty acid supplementation in Americans of African progenitors [113]. Therefore, this kind of food might enhance the efficacy of $\omega-3$ fatty acid supplements [113].

While the anticancer effect of omega-3 polyunsaturated fatty acids (omega-3 fatty acids), particularly eicosapentaenoic acid (EPA) and docosahexaenoic acid (DHA), has been intensely studied, according to Jing et al, our understanding of the underlying mechanisms of omega-3 fatty acids against cancer is still limited [114]. Recent studies describing the protective effect against cancer of EPA and DHA have raised renewed interest in the use of these fatty acids for cancer prevention and treatment [114].

Cho et al. [115] found that colon cancer cell apoptosis is caused by combined exposure to the $\mathrm{n}-3$ fatty acid docosahexaenoic acid and butyrate through promoter methylation.

\section{FETAL PROGRAMMING HYPOTHESIS}

Fetal development is proved a very complex process. At different stages of development different aspects can be changed by specific outside influences. This means that external factors can actually affect the development of the fetus, and some of these changes can last for life. Some substances/chemicals that can harm fetal development are well known and include: j) too much alcohol during pregnancy, which possibly brings to fetal alcohol syndrome; it should be emphasized that even small amounts of alcohol might impact on brain development; jj) smoking during pregnancy can slow the growth of the fetus and also affects some aspects of the development of the brain; jjj) the drug thalidomide can disrupt the development of the limbs leading to physical deformity and disability.

The fetal programming hypothesis is based on the following: $\mathrm{j}$ ) the environment in the uterus, during different sensitive periods for specific outcomes, can alter the development of the fetus, with a permanent effect on the child; jj) quite subtle changes due, for example to altered nutrition, or maternal stress might alter fetal devolopment. The effects of these changes sometimes show up later on; jjj) in the first few weeks the physical structures of the embryo in the uturus are being formed. That is why the drug thalidomide had an effect on the development of arms and legs, only if it was taken early in pregnancy. Vice versa, the brain is being formed all through pregnancy and its development can be affected even at later stages; jjjj) the way by wich the embryo grows in theuterus is important too. Growing more slowly does not just affect early life. It can impact health throughout life, even in old age.

The advanced fetal programming hypothesis proposes an additional non-environmentally driven mechanism: maternal and also paternal genes may influence the maturating sperm, the oocyte, and later the embryo/fetus, leading to their epigenetic alteration [116]. Thus, the observed phenotype of the offspring may be modified by maternal/paternal genes independently from the fetal genome. Meanwhile, several independent association studies in humans focusing on metabolic and neurological traits also suggest that maternal genes might affect the offspring phenotype independent of the transmission of that particular gene to the offspring. Considering the implications of this hypothesis, some conclusions drawn from transgenic or knockout animal models and based on the causality between a genetic 
alteration and a phenotype, need to be challenged. Consequently, possible implications for the development, diagnostic and therapy of human genetic diseases should to be investigated [116].

Unfortunately there is only limited evidence to lend credence to the 'fetal overnutrition hypothesis' [117]. However, recently, it has been showed that poor diet quality during pregnancy increases neonatal adiposity independent of maternal pre-pregnancy BMI and total caloric intake. This aspect further brings to surface that maternal diet is a potentially important exposure for fetal adiposity [118]. Furthermore, maternal obesity and malnutrition-induced oxidative stress could predispose offspring to metabolic syndrome and insulin resistance [119].

Taheripour et al. suggested that a high energy gestational diet can be central to the development of the offspring's vascular function, predisposing them to endothelial dysfunction. This dysfunction may lead to atherosclerotic disease development later in life [120].

Visentin et al. [121] showed that in utero identification of high risk fetuses and long-term follow-up are necessary to assess the effects of interventions aimed at j) reducing maternal obesity, jj) preventing pregnancyinduced hypertension, jji) preventing childhood obesity on adult blood pressure and cardiovascular disease in later life and jjjj) encouraging a healthy life style.

Faienza et al showed that NAFLD should be recognized as an emerging problem in prepubertal children who presented a rapid weight gain in postnatal life, playing insulin resistance a key role. An appropriate diet during pregnancy and in the first year of life might prevent metabolic syndrome and NAFLD in these subjects [122].

\section{FUTURE PERSPECTIVES}

Current evidence strongly suggests that chronic inflammation is a landmark of obesity, atherosclerosis, and NAFLD, and that markers of inflammation are important predictors of cardiovascular risk factors. A crucial question is how proinflammatory gene expression patterns are established and maintained in obesity, atherosclerosis, and NAFLD. Epigenetic gene regulation is a partially new kid on the block in the field of cardiovascular disease. Epigenetics provides attractive candidate disease mechanisms, as it in principle explains how diet, environment and lifestyle can impose aberrant gene expression patterns during an individual's lifespan; even this is the result of transgenerational epigenetic inheritance [123, 124]. The importance of epigenetics in cardiovascular diseases has been suggested by the association of aberrant DNA methylation, one of the epigenetic modifications of the genome, with predisposition to, and natural history of, obesity, atherosclerosis and NAFLD [125]. These correlative studies need to be complemented by strong populationbased and experimental evidence demonstrating a causative role of DNA methylation in atherogenesis.

Atherosclerosis is a progressive human pathology that encompasses several steps in its developing process [126]. Endothelial dysfunction represents an early sign of lesion within the arterial vasculature [126]. A number of risk factors for atherosclerosis, including hyperlipidemia, diabetes, and hypertension, target the vascular endothelium by re-programming its transcriptome, as suggested by $\mathrm{Xu}$ [126].

Environmental and genetic factors interact to produce the NAFLD phenotype and determine its progression. The investigation into the potential roles of epigenetics in NAFLD is just at the beginning and should be completed. The accumulation of genetic and epigenetic knowledge related to this condition has provided novel insight into disease pathogenesis, and may help develop new diagnostic biomarkers and therapeutic targets for the management of NAFLD.

Remely et al. [127] suggested that changes in gut microbiota and, thus, cell wall components are involved in the epigenetic regulation of inflammatory reactions. An improved diet targeted to induce gut microbial balance and possibly even epigenetic changes of pro-inflammatory genes may be effective in the prevention of MS, as reported by Remely et al. [127].

In fact, the human gut microbiota and microbial influences on lipid and glucose metabolism, satiety, and chronic low-grade inflammation are known to be involved in the MetS [128]. Modification in the composition of gut microbiota and/or its biochemical capacity by specific dietary or pharmacological interventions may advantageously affect host metabolism [129]. Large-scale intervention trials investigating the potential benefit of prebiotics and probiotics in improving cardiometabolic health in high-risk populations, are fervently awaited [129]. Although probiotics and prebiotics have been proposed in the treatment and prevention of patients with obesity-related NAFLD, their therapeutic use is not supported by high-quality clinical studies, although an effective short-term treatment for NAFLD, as part of a multidisciplinary approach, has been claimed [130].

A key role could be played by the restoration of a correct enterohepatic circulation of bile acids, which are required for efficient absorption of dietary fat and fat-soluble vitamins, and are involved in the control of high-density and very low-density lipoproteins [131]. Furthermore, a correct secondary bile acid metabolism, the regulation of bile acid synthesis, and the equilibrium of lipid peroxidation, are central to maintaining the intestinal barrier function and the luminal environment, ultimately leading to decreased bacterial translocation [131]. 


\section{CONCLUSION}

The MS represents a cluster of cardiometabolic risk factors, including central obesity, insulin resistance, glucose intolerance, dyslipidemia, hypertension, hyperinsulinemia and microalbuminuria. Although the definition of the MS as well as the single criterion for identifying this condition is still being debated due to the lack of a unifying underlying mechanism, the prevalence of a MS phenotype is rapidly increasing worldwide [125]. Several studies have provided evidence of epigenetic modifications resulting from nutrition during early development, which mediate future and persistent changes in the expression of key metabolic genes contributing to determine an adult MS phenotype [125].

During the past decade, the role of epigenetic mechanisms in the pathogenesis of diseases has been increasingly recognized. Epigenetic modifications, typically including miRNAs, DNA methylation, histone modification and ubiquitination, refer to phenotypic changes induced by mechanisms unrelated to changes in the underlying DNA sequence.

The main long-term goals in this field are the identification and understanding of the role of epigenetic marks that could be used as early predictors of metabolic risk and the development of drugs or diet-related treatments able to delay these changes, and eventually reverse them [132]. However, weight gain and insulin resistance/diabetes are influenced by factors other than epigenetics [132]. The characterization of all the factors able to modify the epigenetic signatures and the determination of their real importance are hampered by three findings, i.e., the extent of the changes produced by dietary and environmental factors is relatively small and mostly cumulative; the cell types studied vary greatly; many factors with multiple interactions between themselves, such as age, are involved [132].

Therefore, a continued and greater understanding of these mechanisms will eventually help identify subjects at high risk of MS, and lead to the development of therapeutic interventions, in accordance with current global government strategy [125], utilizing also food constituents as PUFAs. In fact, there is recent evidence that PUFAs may modulate the promotor epigenetic marks in several adipogenic genes and regulate the expression of several miRNAs [133].

\section{Abbreviations}

Non-alcoholic fatty liver diseases (NAFLD), microRNAs (miRNAs, miRs), polyunsaturated fatty acids (PUFAs), melanocortin 4 receptor (MC4R), insulin-like growth factor-1 (IGF-1), insulin receptor substrate (IRS)-1, vascular endothelial growth factor (VEGF)-A, peroxisome proliferator-activated receptor-gamma (PPARgamma), lipoprotein lipase (LPL), cholesterol (Chol), Toll-like receptor (TLR), apolipoprotein E (ApoE), nuclear factor$\kappa \mathrm{B} / \mathrm{DNA}$ methyltransferase 1 (NF- $\kappa \mathrm{B} / \mathrm{DNMT} 1$ ), monocyte chemoattractant protein-1 (MCP-1), San-Huang-XieXin-Tang (SHXXT), oxidized low-density lipoprotein (oxLDL), human aortic smooth muscle cell (HASMC), matrix metalloproteinase (MMP)-2/MMP-9, DNA methyltransferase 3b (DNMT3b), miRNA-29b (miR-29b), low-density lipoprotein (LDL), Kruppel-like Factor 2 (KLF2), metabolic syndrome (MS), microRNA-122 (miR122), non-alcoholic steatohepatitis (NASH), Enhancer of Zeste Homolog 2 (EZH2), 3-Deazaneplanocin A (DZNep), mitochondrially encoded NADH dehydrogenase 6 (MTND6), drug-activated gene overexpressed (DRAGO), WW domain-containing oxidoreductase (WWOX), long-chain polyunsaturated fatty acids (LCPUFA), plasma membrane (PM), cholesterol (Chol), docosahexaenoic acid (DHA), stearoyl-CoA desaturase-1 (SCD-1), specialized proresolving lipid mediators (SPMs), lipoxins (LX), resolvins $(\mathrm{Rv})$, protectins (PD), maresins (MaR), G-protein coupled receptors (GPCRs) eicosapentaenoic acid (EPA).

All authors gave final approval of the version to be published.

\section{CONFLICTS OF INTEREST}

The authors declare that there are no conflicts of interest.

\section{REFERENCES}

1. Egger G, Liang G, Aparicio A, Jones PA. Epigenetics in human disease and prospects for epigenetic therapy. Nature. 2004; 429: 457-463.

2. Bhaumik SR, Smith E, Shilatifard A. Covalent modifications of histones during development and disease pathogenesis. Nat Struct Mol Biol. 2007; 14 : 1008-1016.

3. Zhang D, Xie X, Chen Y, Hammock BD, Kong W, Zhu Y. Homocysteine upregulates soluble epoxide hydrolase in vascular endothelium in vitro and in vivo. Circ Res. 2012; 110: 808-817.

4. Alexeeff SE, Baccarelli AA, Halonen J, Coull BA, Wright RO, Tarantini L, Bollati V, Sparrow D, Vokonas P, Schwartz J. Association between blood pressure and DNA methylation of retrotransposons and pro-inflammatory genes. Int J Epidemiol. 2013; 42: 270-280.

5. Liu H, Wang T, Liu H, Wei Y, Zhao G, Su J, Wu Q, Qiao $\mathrm{H}$, Zhang Y. Detection of type 2 diabetes related modules and genes based on epigenetic networks. BMC Syst Biol. 2014; $8:$ S5.

6. Herman JJ, Spencer HG, Donohue K, Sultan SE. How stable 'should' epigenetic modifications be? Insights from adaptive plasticity and bet hedging. Evolution. 2014; 68: 632-643. 
7. Bienertová-Vašků J, Nečesánek I, Novák J, Vinklárek J, Zlámal F. "Stress entropic load" as a transgenerational epigenetic response trigger. Med Hypotheses. 2014; 82: 271-274.

8. Jang H, Serra C. Nutrition, Epigenetics, and Diseases. Clin Nutr Res. 2014; 3: 1-8.

9. Marian AJ. The enigma of genetics etiology of atherosclerosis in the post-GWAS era. Curr Atheroscler Rep. 2012; 14: 295-299.

10. Georgakilas G, Vlachos IS, Zagganas K, Vergoulis T, Paraskevopoulou MD, Kanellos I, Tsanakas P, Dellis D, Fevgas A, Dalamagas T, Hatzigeorgiou AG. DIANAmiRGen v3.0: accurate characterization of microRNA promoters and their regulators. Nucleic Acids Res. 2016; 44: D190-195.

11. Tarantino G, Finelli C, Colao A, Capone D, Tarantino M, Grimaldi E, Chianese D, Gioia S, Pasanisi F, Contaldo F, Scopacasa F, Savastano S. Are hepatic steatosis and carotid intima media thickness associated in obese patients with normal or slightly elevated gamma-glutamyl-transferase? J Transl Med. 2012; 10: 50.

12. Ye H, Liu W. Transcriptional networks implicated in human nonalcoholic fatty liver disease. Mol Genet Genomics. 2015; 290: 1793-1804.

13. Sun X, Feinberg MW. MicroRNA-management of lipoprotein homeostasis. Circ Res. 2014; 115: 2-6.

14. Berindan-Neagoe I, Monroig Pdel C, Pasculli B, Calin GA. MicroRNAome genome: a treasure for cancer diagnosis and therapy. CA Cancer J Clin. 2014; 64: 311-336. 15. Liu J, Wu CP, Lu BF, Jiang JT. Mechanism of T cell regulation by microRNAs. Cancer Biol Med. 2013; 10: 131-137.

16. Tessitore A, Cicciarelli G, Del Vecchio F, Gaggiano A, Verzella D, Fischietti M, Vecchiotti D, Capece D, Zazzeroni F, Alesse E. MicroRNAs in the DNA Damage/ Repair Network and Cancer. Int J Genomics. 2014; 2014: 820248.

17. Vimalraj S, Selvamurugan N. MicroRNAs expression and their regulatory networks during mesenchymal stem cells differentiation toward osteoblasts. Int J Biol Macromol. 2014; 66: 194-202. 18. Finelli C, Tarantino G. Is visceral fat reduction necessary to favour metabolic changes in the liver? J Gastrointestin Liver Dis. 2012; 21: 205-208.

19. Finelli C, Tarantino G. Should visceral fat, strictly linked to hepatic steatosis, be depleted to improve survival? Hepatol Int 2012; 7: 413-428

20. Tarantino G, Finelli C. What about non-alcoholic fatty liver disease as a new criterion to define metabolic syndrome? World J Gastroenterol. 2013; 19 : 3375-3384.

21. Finelli C, Sommella L, Gioia S, La Sala N, Tarantino G. Should visceral fat be reduced to increase longevity? Ageing Res Rev. 2013; 12: 996-1004.

22. Tarantino G, Finelli C. Pathogenesis of hepatic steatosis: The link between hypercortisolism and non-alcoholic fatty liver disease. World J Gastroenterol. 2013; 19: 6735-6743.
23. Labruna G, Pasanisi F, Nardelli C, Tarantino G, Vitale DF, Bracale R, Finelli C, Genua MP, Contaldo F, Sacchetti L. UCP1 -3826 AG+GG genotypes, adiponectin and leptin/ adiponectin ratio in severe obesity. J Endocrinol Invest. 2009; 32: 525-529.

24. Splichal Z, Bienertova-Vasku J, Novak J, Zlamal F, Tomandl J, Tomandlova M, Forejt M, Havlenova S, Jackowska A, Vasku A. The common polymorphism Val109Asp in the omentin gene is associated with daily energy intake in the Central-European population. Nutr Neurosci. 2015; 18: 41-48.

25. Ahasic AM, Zhao Y, Su L, Sheu CC, Thompson BT, Christiani DC. Adiponectin gene polymorphisms and acute respiratory distress syndrome susceptibility and mortality. PLoS One. 2014; 9: e89170.

26. Baldani DP, Skrgatic L, Cerne JZ, Ferk P, Simunic V, Gersak K. Association of PPARG Pro12Ala polymorphism with insulin sensitivity and body mass index in patients with polycystic ovary syndrome. Biomed Rep. 2014; 2: 199-206.

27. Lasram K, Ben Halim N, Benrahma H, Mediene-Benchekor S, Arfa I, Hsouna S, Kefi R, Jamoussi H, Ben Ammar S, Bahri S, Abid A, Benhamamouch S, Barakat A, et al.. Contribution of CDKAL1 rs7756992 and IGF2BP2 rs4402960 polymorphisms in Type 2 diabetes, diabetic complications, obesity risk and hypertension in the Tunisian population. J Diabetes. 2015; 7:102-113.

28. Lim KI, Shin YA. Impact of UCP2 polymorphism on longterm exercise-mediated changes in adipocytokines and markers of metabolic syndrome. Aging Clin Exp Res. 2014; 26: 491-496 .

29. Cordero P, Li J, Oben JA. Epigenetics of obesity: beyond the genome sequence. Curr Opin Clin Nutr Metab Care. 2015; 18: 361-366.

30. White MJ, Risse-Adams O, Goddard P, Contreras MG, Adams J, Hu D, Eng C, Oh SS, Davis A, Meade K, BriginoBuenaventura E, LeNoir MA, Bibbins-Domingo K, PinoYanes M, Burchard EG. Novel genetic risk factors for asthma in African American children: Precision Medicine and the SAGE II Study. Immunogenetics. 2016 May 3. [Epub ahead of print]

31. Jing X, Kay S, Marley T, Hardiker NR, Cimino JJ. Incorporating personalized gene sequence variants, molecular genetics knowledge, and health knowledge into an EHR prototype based on the Continuity of Care Record standard. J Biomed Inform. 2012; 45: 82-92.

32. Ahmad S, Zhao W, Renström F, Rasheed A, Zaidi M, Samuel M, Shah N, Mallick NH, Shungin D, Zaman KS, Ishaq M, Rasheed SZ, Memon FU, et al. A novel interaction between the FLJ33534 locus and smoking in obesity: a genome-wide study of 14131 Pakistani adults. Int J Obes (Lond). 2016; 40: 186-190.

33. Hayes MG, Urbanek M, Ehrmann DA, Armstrong LL, Lee JY, Sisk R, Karaderi T, Barber TM, McCarthy MI, Franks $\mathrm{S}$, Lindgren CM, Welt CK, Diamanti-Kandarakis E, et al. Genome-wide association of polycystic ovary syndrome 
implicates alterations in gonadotropin secretion in European ancestry populations. Nat Commun. 2015; 6: 7502.

34. Warrington NM, Howe LD, Paternoster L, Kaakinen M, Herrala S, Huikari V, Wu YY, Kemp JP, Timpson NJ, St Pourcain B, Davey Smith G, Tilling K, Jarvelin MR, et al. . A genome-wide association study of body mass index across early life and childhood. Int J Epidemiol. 2015; 44: $700-712$

35. Nettleton JA, Follis JL, Ngwa JS, Smith CE, Ahmad S, Tanaka T, Wojczynski MK, Voortman T, Lemaitre RN, Kristiansson K, Nuotio ML, Houston DK, Perälä MM, et al. Gene $\times$ dietary pattern interactions in obesity: analysis of up to 68317 adults of European ancestry. Hum Mol Genet. 2015; 24: 4728-4738.

36. Hara K, Fujita H, Johnson TA, Yamauchi T, Yasuda K, Horikoshi M, Peng C, Hu C, Ma RC, Imamura M, Iwata M, Tsunoda T, Morizono T, et al. Genome-wide association study identifies three novel loci for type 2 diabetes. Hum Mol Genet. 2014; 23: 239-246.

37. DIAbetes Genetics Replication And Meta-analysis (DIAGRAM) Consortium; Asian Genetic Epidemiology Network Type 2 Diabetes (AGEN-T2D) Consortium; South Asian Type 2 Diabetes (SAT2D) Consortium; Mexican American Type 2 Diabetes (MAT2D) Consortium; Type 2 Diabetes Genetic Exploration by Nex-generation sequencing in muylti-Ethnic Samples (T2D-GENES) Consortium, Mahajan A, Go MJ, Zhang W, Below JE, Gaulton KJ, Ferreira T, Horikoshi M, Johnson AD, et al. Genome-wide trans-ancestry meta-analysis provides insight into the genetic architecture of type 2 diabetes susceptibility. Nat Genet. 2014; 46: 234-244.

38. Matsuba R, Imamura M, Tanaka Y, Iwata M, Hirose H, Kaku K, Maegawa H, Watada H, Tobe K, Kashiwagi A, Kawamori R, Maeda S. Replication Study in a Japanese Population of Six Susceptibility Loci for Type 2 Diabetes Originally Identified by a Transethnic Meta-Analysis of Genome-Wide Association Studies. PLoS One. 2016; 11: e0154093.

39. Sadakierska-Chudy A, Kostrzewa RM, Filip M. A comprehensive view of the epigenetic landscape part I: DNA methylation, passive and active DNA demethylation pathways and histone variants. Neurotox Res. 2015; 27: 8497.

40. Waterland RA, Michels KB. Epigenetic epidemiology of the developmental origins hypothesis. Annu Rev Nutr. 2007; 27: 363-388.

41. Martínez JA, Milagro FI, Claycombe KJ, Schalinske KL. Epigenetics in adipose tissue, obesity, weight loss, and diabetes. Adv Nutr. 2014; 5: 71-81.

42. Attig L, Vigé A, Gabory A, Karimi M, Beauger A, Gross MS, Athias A, Gallou-Kabani C, Gambert P, Ekstrom TJ, Jais JP, Junien C. Dietary alleviation of maternal obesity and diabetes: increased resistance to diet-induced obesity transcriptional and epigenetic signatures. PLoS One. 2013; 8: e66816.
43. Dick KJ, Nelson CP, Tsaprouni L, Sandling JK, Aïssi D, Wahl S, Meduri E, Morange PE, Gagnon F, Grallert H, Waldenberger M, Peters A, Erdmann J, Hengstenberg C, et al. DNA methylation and body-mass index: a genome-wide analysis. Lancet. 2014; 383: 1990-1998.

44. Gillberg L, Perfilyev A, Brøns C, Thomasen M, Grunnet LG, Volkov P, Rosqvist F, Iggman D, Dahlman I, Risérus U, Rönn T, Nilsson E, Vaag A, Ling C. Adipose tissue transcriptomics and epigenomics in low birthweight men and controls: role of high-fat overfeeding. Diabetologia. 2016; 59: 799-812.

45. Sánchez-Garrido MA, Castellano JM, Ruiz-Pino F, GarciaGaliano D, Manfredi-Lozano M, Leon S, Romero-Ruiz A, Diéguez C, Pinilla L, Tena-Sempere M. Metabolic programming of puberty: sexually dimorphic responses to early nutritional challenges. Endocrinology. 2013; 154: 3387-3400.

46. Drummond EM, Gibney ER. Epigenetic regulation in obesity. Curr Opin Clin Nutr Metab Care. 2013; 16: 392397.

47. Bayol SA, Simbi BH, Bertrand JA, Stickland NC. Offspring from mothers fed a 'junk food' diet in pregnancy and lactation exhibit exacerbated adiposity that is more pronounced in females. J Physiol. 2008; 586: 3219-3230.

48. Tarantino G, Conca P, Pasanisi F, Ariello M, Mastrolia M, Arena A, Tarantino M, Scopacasa F, Vecchione R. Could inflammatory markers help diagnose nonalcoholic steatohepatitis? Eur J Gastroenterol Hepatol. 2009; 21: 504511.

49. Li CC, Young PE, Maloney CA, Eaton SA, Cowley MJ, Buckland ME, Preiss T, Henstridge DC, Cooney GJ, Febbraio MA, Martin DI, Cropley JE, Suter CM. Maternal obesity and diabetes induces latent metabolic defects and widespread epigenetic changes in isogenic mice. Epigenetics. 2013; 8: 602-611.

50. Gilbert ER, Liu D. Epigenetics: the missing link to understanding $\beta$-cell dysfunction in the pathogenesis of type 2 diabetes. Epigenetics. 2012; 7: 841-852.

51. Ruchat SM, Hivert MF, Bouchard L. Epigenetic programming of obesity and diabetes by in utero exposure to gestational diabetes mellitus. Nutr Rev. 2013; 71: S8894.

52. Zheng LD, Linarelli LE, Liu L, Wall SS, Greenawald MH, Seidel RW, Estabrooks PA, Almeida FA, Cheng Z. Insulin resistance is associated with epigenetic and genetic regulation of mitochondrial DNA in obese humans. Clin Epigenetics. 2015; 7: 60.

53. Nicolaou G, Goodall AH, Erridge C. Diverse bacteria promote macrophage foam cell formation via Toll-like receptor-dependent lipid body biosynthesis. J Atheroscler Thromb. 2012; 19: 137-48.

54. Slevin M, Wang Q, Font MA, Luque A, Juan-Babot O, Gaffney J, Kumar P, Kumar S, Badimon L, Krupinski J. Atherothrombosis and plaque heterology: different location 
or a unique disease? Pathobiology. 2008; 75: 209-225.

55. Wierda RJ, Geutskens SB, Jukema JW, Quax PH, van den Elsen PJ. Epigenetics in atherosclerosis and inflammation. J Cell Mol Med. 2010; 14: 1225-1240.

56. Zaina S. Unraveling the DNA methylome of atherosclerosis. Curr Opin Lipidol. 2014; 25: 148-153.

57. Aavik E, Lumivuori H, Leppänen O, Wirth T, Häkkinen SK, Bräsen JH, Beschorner U, Zeller T, Braspenning M, van Criekinge W, Mäkinen K, Ylä-Herttuala S. Global DNA methylation analysis of human atherosclerotic plaques reveals extensive genomic hypomethylation and reactivation at imprinted locus 14q32 involving induction of a miRNA cluster. Eur Heart J. 2015; 36: 993-1000.

58. Jiang $\mathrm{Y}$, Zhang H, Sun $\mathrm{T}$, Wang J, Sun W, Gong H, Yang B, Shi Y, Wei J. The comprehensive effects of hyperlipidemia and hyperhomocysteinemia on pathogenesis of atherosclerosis and DNA hypomethylation in ApoE-/mice. Acta Biochim Biophys Sin (Shanghai). 2012; 44: 866-875.

59. Wang J, Jiang Y, Yang A, Sun W, Ma C, Ma S, Gong H, Shi Y, Wei J. Hyperhomocysteinemia-Induced Monocyte Chemoattractant Protein-1 Promoter DNA Methylation by Nuclear Factor- $\kappa \mathrm{B} / \mathrm{DNA}$ Methyltransferase 1 in Apolipoprotein E-Deficient Mice. Biores Open Access. 2013; 2: 118-127.

60. Ma S, Zhang H, Sun W, Gong H, Wang Y, Ma C, Wang J, Cao C, Yang X, Tian J, Jiang Y. Hyperhomocysteinemia induces cardiac injury by up-regulation of p53-dependent Noxa and Bax expression through the p53 DNA methylation in ApoE (-/-) mice. Acta Biochim Biophys Sin (Shanghai). 2013; 45: 391-400.

61. Delaney C, Garg SK, Fernandes C, Hoeltzel M, Allen RH, Stabler S, Yung R. Maternal diet supplemented with methyl-donors protects against atherosclerosis in F1 ApoE(/-) mice. PLoS One. 2013; 8: e56253.

62. Yoo T, Yoon YS, Ryu SH, Ahn JY, Kim S, Ha TY, Chung $\mathrm{JH}$, Joe CO. Hypermethylation of repetitive DNA elements in livers of mice fed an atherogenic diet. Nutrition. 2012; 28: 127-130.

63. Kim J, Kim JY, Song KS, Lee YH, Seo JS, Jelinek J, Goldschmidt-Clermont PJ, Issa JP. Epigenetic changes in estrogen receptor beta gene in atherosclerotic cardiovascular tissues and in-vitro vascular senescence. Biochim Biophys Acta. 2007; 1772: 72-80.

64. Wang YS, Chou WW, Chen KC, Cheng HY, Lin RT, Juo SH. MicroRNA-152 mediates DNMT1-regulated DNA methylation in the estrogen receptor $\alpha$ gene. PLoS One. 2012; 7: e30635.

65. Chen KC, Wang YS, Hu CY, Chang WC, Liao YC, Dai CY, Juo SH. OxLDL up-regulates microRNA-29b, leading to epigenetic modifications of MMP-2/MMP-9 genes: a novel mechanism for cardiovascular diseases. FASEB J. 2011; 25: 1718-1728.

66. Kumar A, Kumar S, Vikram A, Hoffman TA, Naqvi
A, Lewarchik CM, Kim YR, Irani K. Histone and DNA methylation-mediated epigenetic downregulation of endothelial Kruppel-like factor 2 by low-density lipoprotein cholesterol. Arterioscler Thromb Vasc Biol. 2013; 33: 1936-1942.

67. Yamada Y, Nishida T, Horibe H, Oguri M, Kato K, Sawabe M. Identification of hypo- and hypermethylated genes related to atherosclerosis by a genome-wide analysis of DNA methylation. Int J Mol Med. 2014; 33: 1355-1340.

68. Tarantino G. Non-alcoholic fatty liver disease, obesity and other illnesses. Clin Invest Med. 2008; 31: E290-5.

69. Vernon G, Baranova A, Younossi ZM. Systematic review: the epidemiology and natural history of non-alcoholic fatty liver disease and non-alcoholic steatohepatitis in adults. Aliment Pharmacol Ther. 2011; 34: 274-285.

70. Sherif ZA, Saeed A, Ghavimi S, Nouraie SM, Laiyemo AO, Brim H, Ashktorab H. Global Epidemiology of Nonalcoholic Fatty Liver Disease and Perspectives on US Minority Populations. Dig Dis Sci. 2016 ; 61: 12141225.

71. Finelli C, Tarantino G. Have guidelines addressing physical activity been established in nonalcoholic fatty liver disease? World J Gastroenterol. 2012; 18: 6790-6800.

72. Finelli $\mathrm{C}$, Tarantino G. Is there any consensus as to what diet or lifestyle approach is the right one for NAFLD patients? J Gastrointestin Liver Dis. 2012; 21: 293-302.

73. Colicchio P, Tarantino G, del Genio F, Sorrentino P, Saldalamacchia G, Finelli C, Conca P, Contaldo F, Pasanisi F. Non-alcoholic fatty liver disease in young adult severely obese non-diabetic patients in South Italy. Ann Nutr Metab. 2005; 49: 289-95.

74. Tarantino G, Colicchio P, Conca P, Finelli C, Di Minno MN, Tarantino M, Capone D, Pasanisi F. Young adult obese subjects with and without insulin resistance: what is the role of chronic inflammation and how to weigh it noninvasively? J Inflamm (Lond). 2009; 6: 6.

75. Wainwright P, Byrne CD. Bidirectional Relationships and Disconnects between NAFLD and Features of the Metabolic Syndrome. Int J Mol Sci. 2016 Mar 11;17(3). pii: E367. doi: 10.3390/ijms17030367. 76. Lee JH, Friso S, Choi SW. Epigenetic mechanisms underlying the link between non-alcoholic fatty liver diseases and nutrition. Nutrients. 2014; 6: 3303-25.

77. Sun C, Fan JG, Qiao L. Potential epigenetic mechanism in non-alcoholic Fatty liver disease. Int J Mol Sci. 2015; 16: 5161-5179.

78. Aguilar-Olivos NE, Oria-Hernández J, Ponciano-Rodríguez G, Chávez-Tapia NC, Uribe M, Méndez-Sánchez N. The Role of Epigenetics in the Progression of Non-Alcoholic Fatty Liver Disease. Mini Rev Med Chem. 2015; 15: 11871194.

79. Gallego-Durán R, Romero-Gómez M. Epigenetic mechanisms in non-alcoholic fatty liver disease: An emerging field. World J Hepatol. 2015; 7: 2497-2502. . 
80. Zarfeshani A, Ngo S, Sheppard AM. MicroRNA Expression Relating to Dietary-Induced Liver Steatosis and NASH. J Clin Med. 2015; 4: 1938-1950.

81. Szabo G, Csak T. Role of MicroRNAs in NAFLD/NASH. Dig Dis Sci. 2016; 61: 1314-1324.

82. Lakner AM, Bonkovsky HL, Schrum LW. microRNAs: fad or future of liver disease. World J Gastroenterol. 2011; 17: 2536-2542.

83. Bei Y, Song Y, Wang F, Dimitrova-Shumkovska J, Xiang Y, Zhao Y, Liu J, Xiao J, Yang C. miR-382 targeting PTEN-Akt axis promotes liver regeneration. Oncotarget. 2016; 7: 1584-1597.

84. Miyaaki H, Ichikawa T, Kamo Y, Taura N, Honda T, Shibata H, Milazzo M, Fornari F, Gramantieri L, Bolondi L, Nakao K. Significance of serum and hepatic microRNA-122 levels in patients with non-alcoholic fatty liver disease. Liver Int. 2014; 34: e302-7.

85. Salvoza NC, Klinzing DC, Gopez-Cervantes J, Baclig MO. Association of Circulating Serum miR-34a and miR-122 with Dyslipidemia among Patients with Non-Alcoholic Fatty Liver Disease. PLoS One. 2016; 11: e0153497.

86. Zhang Y, Cheng X, Lu Z, Wang J, Chen H, Fan W, Gao X, Lu D. Upregulation of miR-15b in NAFLD models and in the serum of patients with fatty liver disease. Diabetes Res Clin Pract. 2013; 99: 327-334.

87. Estep M, Armistead D, Hossain N, Elarainy H, Goodman Z, Baranova A, Chandhoke V, Younossi ZM. Differential expression of miRNAs in the visceral adipose tissue of patients with non-alcoholic fatty liver disease. Aliment Pharmacol Ther. 2010; 32: 487-497.

88. Yang Z, Cappello T, Wang L. Emerging role of microRNAs in lipid metabolism. Acta Pharm Sin B. 2015; 5: 145150.

89. Vella S, Gnani D, Crudele A, Ceccarelli S, De Stefanis C, Gaspari S, Nobili V, Locatelli F, Marquez VE, Rota R, Alisi A. EZH2 down-regulation exacerbates lipid accumulation and inflammation in in vitro and in vivo NAFLD. Int J Mol Sci. 2013; 14: 24154-24168.

90. Pirola CJ, Gianotti TF, Burgueño AL, Rey-Funes M, Loidl CF, Mallardi P, Martino JS, Castaño GO, Sookoian $\mathrm{S}$. Epigenetic modification of liver mitochondrial DNA is associated with histological severity of nonalcoholic fatty liver disease. Gut. 2013; 62: 1356-1363.

91. Xiao J, Bei Y, Liu J, Dimitrova-Shumkovska J, Kuang D, Zhou Q, Li J, Yang Y, Xiang Y, Wang F, Yang C, Yang W. miR-212 downregulation contributes to the protective effect of exercise against non-alcoholic fatty liver via targeting FGF-21. J Cell Mol Med. 2016; 20: 204-216.

92. Bruce KD, Cagampang FR, Argenton M, Zhang J, Ethirajan PL, Burdge GC, Bateman AC, Clough GF, Poston L, Hanson MA, McConnell JM, Byrne CD. Maternal highfat feeding primes steatohepatitis in adult mice offspring, involving mitochondrial dysfunction and altered lipogenesis gene expression. Hepatology. 2009; 50: 1796-1808.
93. Sleiman D, Al-Badri MR, Azar ST. Effect of mediterranean diet in diabetes control and cardiovascular risk modification: a systematic review. Front Public Health. 2015; 3: 69.

94. Aljefree N, Ahmed F. Association between dietary pattern and risk of cardiovascular disease among adults in the Middle East and North Africa region: a systematic review. Food Nutr Res. 2015; 59: 27486.

95. Maraki M, Sidossis LS. Update on lifestyle determinants of postprandial triacylglycerolemia with emphasis on the Mediterranean lifestyle. Am J Physiol Endocrinol Metab. 2015; 309: E440-449.

96. Bonaccio M, Di Castelnuovo A, De Curtis A, Costanzo S, Bracone F, Persichillo M, Donati MB, de Gaetano G, Iacoviello L. Nut consumption is inversely associated with both cancer and total mortality in a Mediterranean population: prospective results from the Moli-sani study. Br J Nutr. 2015; 114: 804-811. .

97. Georgoulis M, Kontogianni MD, Margariti A, Tiniakos D, Fragopoulou E, Zafiropoulou R, Papatheodoridis G. Associations between dietary intake and the presence of the metabolic syndrome in patients with non-alcoholic fatty liver disease. J Hum Nutr Diet. 2015; 28:409-415. 98.

Sijben JW, Calder PC. Differential immunomodulation with long-chain n-3 PUFA in health and chronic disease. Proc Nutr Soc. 2007; $66: 237-259$.

99 Lee HS, Barraza-Villarreal A, Hernandez-Vargas H, Sly PD, Biessy C, Ramakrishnan U, Romieu I, Herceg Z. Modulation of DNA methylation states and infant immune system by dietary supplementation with $\omega-3$ PUFA during pregnancy in an intervention study. Am J Clin Nutr. 2013; 98: 480-487.

100. Suárez-Álvarez B, Baragaño Raneros A, Ortega F, LópezLarrea C. Epigenetic modulation of the immune function: a potential target for tolerance. Epigenetics. 2013; 8: 694-702.

101. Dunn J, McCuaig R, Tu WJ, Hardy K, Rao S. Multilayered epigenetic mechanisms contribute to transcriptional memory in T lymphocytes. BMC Immunol. 2015; 16: 27. 102. Berni Canani R, Paparo L, Nocerino R, Cosenza L, Pezzella V, Di Costanzo M, Capasso M, Del Monaco V, D’Argenio V, Greco L, Salvatore F. Differences in DNA methylation profile of Th1 and Th2 cytokine genes are associated with tolerance acquisition in children with IgEmediated cow's milk allergy. Clin Epigenetics. 2015; 7: 38.

103. MacGillivray DM, Kollmann TR. The role of environmental factors in modulating immune responses in early life. Front Immunol. 2014; 5: 434.

104. Busch C, Burkard M, Leischner C, Lauer UM, Frank J, Venturelli S. Epigenetic activities of flavonoids in the prevention and treatment of cancer. Clin Epigenetics. 2015; 7: 64 .

105. Liu Y, Zhang Q, Ding Y, Li X, Zhao D, Zhao K, Guo Z, Cao X. Histone lysine methyltransferase Ezh1 promotes TLR-triggered inflammatory cytokine production by suppressing Tollip. J Immunol. 2015; 194: 2838-2846. 
106. Prescott SL. Early-life environmental determinants of allergic diseases and the wider pandemic of inflammatory noncommunicable diseases. J Allergy Clin Immunol. 2013; 131: 23-30.

107. Surette ME. Dietary omega-3 PUFA and health: stearidonic acid-containing seed oils as effective and sustainable alternatives to traditional marine oils. Mol Nutr Food Res. 2013; 57: 748-759.

108. Di Minno MN, Russolillo A, Lupoli R, Ambrosino P, Di Minno A, Tarantino G. Omega-3 fatty acids for the treatment of non-alcoholic fatty liver disease. World $\mathrm{J}$ Gastroenterol. 2012; 18: 5839-5847.

109. Jaureguiberry MS, Tricerri MA, Sanchez SA, Finarelli GS, Montanaro MA, Prieto ED, Rimoldi OJ. Role of plasma membrane lipid composition on cellular homeostasis: learning from cell line models expressing fatty acid desaturases. Acta Biochim Biophys Sin (Shanghai). 2014; 46: 273-282.

110. Huang LL, Wan JB, Wang B, He CW, Ma H, Li TW, Kang JX. Suppression of acute ethanol-induced hepatic steatosis by docosahexaenoic acid is associated with downregulation of stearoyl-CoA desaturase 1 and inflammatory cytokines. Prostaglandins Leukot Essent Fatty Acids. 2013; 88: $347-$ 353.

111. Recchiuti A, Serhan CN. Pro-Resolving Lipid Mediators (SPMs) and Their Actions in Regulating miRNA in Novel Resolution Circuits in Inflammation. Front Immunol. 2012; 3: 298 .

112. Jones ML, Mark PJ, Waddell BJ. Maternal dietary omega-3 fatty acids and placental function. Reproduction. 2014; 147 : R143-52.

113. O’Sullivan A, Armstrong P, Schuster GU, Pedersen TL, Allayee H, Stephensen CB, Newman JW. Habitual diets rich in dark-green vegetables are associated with an increased response to $\omega-3$ fatty acid supplementation in Americans of African ancestry. J Nutr. 2014; 144: 123-131.

114. Jing K, Wu T, Lim K. Omega-3 polyunsaturated fatty acids and cancer. Anticancer Agents Med Chem. 2013; 13: 11621177

115. Cho Y, Turner ND, Davidson LA, Chapkin RS, Carroll RJ, Lupton JR. Colon cancer cell apoptosis is induced by combined exposure to the n-3 fatty acid docosahexaenoic acid and butyrate through promoter methylation. Exp Biol Med (Maywood). 2014; 239: 302-310.

116. Hocher B. More than genes: the advanced fetal programming hypothesis. J Reprod Immunol. 2014; 104105: 8-11.

117. Patro B, Liber A, Zalewski B, Poston L, Szajewska H, Koletzko B. Maternal and paternal body mass index and offspring obesity: a systematic review. Ann Nutr Metab. 2013; 63: 32-41.

118. Shapiro AL, Kaar JL, Crume TL, Starling AP, Siega-Riz AM, Ringham BM, Glueck DH, Norris JM, Barbour LA, Friedman JJ, Dabelea D. Maternal diet quality in pregnancy and neonatal adiposity: The healthy start study. Int J Obes (Lond). 2016 Jun 7. [Epub ahead of print]

119. Saad MI, Abdelkhalek TM, Haiba MM, Saleh MM, Hanafi MY, Tawfik SH, Kamel MA. Maternal obesity and malnourishment exacerbate perinatal oxidative stress resulting in diabetogenic programming in F1 offspring. J Endocrinol Invest. 2016; 39: 643-655. 120. Taheripour P, DeFord MA, Arentson-Lantz EJ, Donkin SS, Ajuwon KM, Newcomer SC. Impact of excess gestational and post-weaning energy intake on vascular function of swine offspring. BMC Pregnancy Childbirth. 2014; 14: 405.

121. Visentin S, Grumolato F, Nardelli GB, Di Camillo B, Grisan E, Cosmi E. Early origins of adult disease: low birth weight and vascular remodeling. Atherosclerosis. 2014; 237: 391-399.

122. Faienza MF, Brunetti G, Ventura A, D'Aniello M, Pepe T, Giordano P, Monteduro M, Cavallo L. Nonalcoholic fatty liver disease in prepubertal children born small for gestational age: influence of rapid weight catch-up growth. Horm Res Paediatr. 2013; 79: 103-109.

123. Morgan DK, Whitelaw E. The role of epigenetics in mediating environmental effects on phenotype. Nestle Nutr Workshop Ser Pediatr Program. 2009; 63: 109-117.124.

Koletzko B, Brands B, Poston L, Godfrey K, Demmelmair $\mathrm{H}$; Early Nutrition Project. Early nutrition programming of long-term health. Proc Nutr Soc. 2012; 71: 371-378.

125. Bruce KD, Cagampang FR. Epigenetic priming of the metabolic syndrome. Toxicol Mech Methods. 2011; 21: 353-361.

126. Xu Y. Transcriptional regulation of endothelial dysfunction in atherosclerosis: an epigenetic perspective. J Biomed Res. 2014; 28: 47-52.

127. Remely M, Aumueller E, Jahn D, Hippe B, Brath H, Haslberger AG. Microbiota and epigenetic regulation of inflammatory mediators in type 2 diabetes and obesity. Benef Microbes. 2014; 5: 33-43.

128. Remely M, Aumueller E, Merold C, Dworzak S, Hippe B, Zanner J, Pointner A, Brath H, Haslberger AG. Effects of short chain fatty acid producing bacteria on epigenetic regulation of FFAR3 in type 2 diabetes and obesity. Gene. 2014; 537: 85-92.

129. Finelli C, Tarantino G. Non-alcoholic fatty liver disease, diet and gut microbiota. EXCLI Journal 2014; 13: 461-490

130. Tarantino G, Finelli C. Systematic review on intervention with prebiotics/probiotics in patients with obesity-related nonalcoholic fatty liver disease. Future Microbiol. 2015; 10: 889-902.

131. Tarantino G. Gut microbiome, obesity-related comorbidities, and low-grade chronic inflammation. J Clin Endocrinol Metab. 2014; 99: 2343-2346.

132. Martínez JA, Milagro FI, Claycombe KJ, Schalinske KL. Epigenetics in adipose tissue, obesity, weight loss, and diabetes. Adv Nutr. 2014; 5: 71-81. 
133. Hernando Boigues JF, Mach N. The effect of polyunsaturated fatty acids on obesity through epigenetic modifications. Endocrinol Nutr. 2015; 62: 338-349. 